\title{
Investigation and Research on the Emotional Anxiety Current Situation of Learners in Flipped Classroom
}

\author{
Jingjing Shi \\ School of Foreign Studies, Xi'an University, 710065
}

Keywords: Flipped Classroom; Learners; Emotion Anxiety

\begin{abstract}
Flipped classroom is also known as inverted classroom. It is a new requirement and teaching method proposed in new curriculum reform which hopes to transfer the initiative from teachers to students. This modern learning mode can make students take advantage of the valuable time inside and outside the classroom and concentrate on learning by themselves. Flipped classroom liberates learners from traditional practice. But learners may show a certain emotional anxiety in the process of learning to be knowledge probiotics. In the process of changing from traditional receptive learning method to modern self-regulation learning strategy, learners would be anxious under the feeling of self-efficacy and flipped classroom. This paper will discuss how to improve learners' self-promotion consciousness, enhance the positive meaning of flipped classroom teaching quality and study how to carry out emotional education self-regulation method.
\end{abstract}

\section{Introduction}

Learner factor is a part of teaching design and is also known as learner characteristics which mainly includes cognitive characteristics, learning starting level, learning interest, learning style and personality characteristics, etc. Under the traditional teaching philosophy, learners have always been in a passive marginal status as teachers are the core of teaching. But there are more and more people concerned about the human factors in behavioral activities. Therefore, in the flipped classroom teaching process, in order to improve the efficiency of teaching activities and save cost, it is necessary to understand the emotional anxiety of learners. If learners continue to be anxious under the new knowledge transfer mode, emotional anxiety will reduce their self-efficacy and learning efficiency and make the learning effect be worse.

\section{The Background and Meaning of the Flipped Classroom}

The background of flipped classroom is based on the deep integration of information technology and education. This new kind of information technology teaching environment and optimized teaching mode can be very good to promote education reform forward. The key point of the new curriculum reform is to make students as the main learning subject. Students can learn to reflect by themselves, sparkplug teaching plans and learn autonomous and collaborative inquiry learning patterns, understand the relationship between educational mode and teaching reform for the rollover classroom project. In this context, flipped classroom teaching process and research starting point are guided by the basis of teaching process theory and analyze the characteristics of teaching process. Whether it is feasible for the research objects of design analysis solutions and the development of classroom teaching video, the role of flipped classroom in teaching process can be analyzed by focusing on students' learning motivation, interests and active participation degree on learning.

The Fundamental Status and Development Background of Learner Factor. A great development dimension of flipped classroom is to make use of modern multimedia technology, internet environment interactive computer and mobile phone intelligent terminal equipment electronic information exchange technology to help teachers and study researchers effectively use classroom resources and make the important reorganization of classroom resources as a start to change the traditional way of teaching in the study of the new era of teaching background. The early flipped classroom actually combine video resources with teaching methods for students to carry out special counseling. And later people gradually use the teaching resources of flipped classroom. Use 
the approach of information technology and educational resources to guide an educational revolution. This kind of video resource-based new teaching mode is flipped classroom educational mode.

The Change of Traditional Education and the Teaching Consideration of Emotional Factors. The rapid advance of quality-oriented education makes the main role of teachers and students have changed dramatically in education activities. The transformation of traditional teaching teachers as a carrier of knowledge is a change and improvement which is change and improvement of the mastery of teaching activities and improvement of teaching objects for teacher. In other words, teachers concerned about the student's academic performance most previously and teachers have paid more attention to students' grasp of learning methods at present. They are no longer the implementer of teaching textbook but should be creative use of a variety of teaching methods to use the textbook and communicate and cooperation with students. Work with students to explore a new type of teacher-student relationship between democracy and equality, harmony and interaction. It is a bold trial for teachers and students to communicate with each other, inspired and supplementary study bold attempt in education process.

Learners' learning emotion and anxiety are important factors that affect learning efficiency. In the modernization of the new teaching model especially the flipped classroom, it has aroused widespread concern of educational researchers. Anxiety is a normal, common psychological tension. When people encounter certain challenges, difficulties or unknown things, an abnormal emotional reaction may be shown. Learning anxiety may be caused by tension and can't carry out normal learning and play a normal level of learning. Through psychological studies, it is shown that learners' anxiety is a relatively complex problem for learning. The relationship between learners' anxiety degree and learning efficiency is the development of inverted U-shaped curves. Anxiety degree too strong or weak will both decrease the learning efficiency. Satisfying the best learning efficiency anxiety balance is a matter of concern to many educational learners.

The Time Feature and Development of Flipped Classroom. Flipped classroom is a combination of the development for the change in new era. It is a mode change surround teaching video and educational philosophy. Today is a diversified information age: the Internet era, Wechat era, Taobao era, cloud era and internet of things era... This era will make great changes to learning style. It is the era of combining mobile learning with the Internet technologies. It can provide unlimited possibilities for the development of education and will transform the classroom into a platform of extracurricular, mobile, digital learning and teaching. Based on this, the research on flipped classroom teaching process supported by information technology support under the flipped classroom teaching process research is an important issue. In other words, flipped classroom combined with new educational reform needs and meet the needs of modern educational resources sharing under this diversified information background. Make use of high-quality teaching resources on the internet to shake the traditional classroom teacher-centered teaching mode. It wants to undertake student effectiveness and adaptability of learning purposes. According to the students self-learning awareness and ability of the actual situation, the appropriate use of flipped classroom to reduce the burden of learning and enhance the efficiency of student.

Role Swap Overturned between Teacher and Student in Flipped Classroom. Teachers share experience and exchange emotional experience with each other. Guide students with their own profound knowledge so that students would consciously imitate their behaviors and the entire teaching activities would also be more democratic and relaxed. Teachers innovatively respect personality and dignity of students and talk with them in good faith in the teaching process. They change the teaching habits in the past and complete the new teaching process properly with a harmonious teaching atmosphere. This is effective change of traditional teaching concept. The teaching mode of the flipped classroom is the sum of various forms of synthesis in which teachers and students are expected to participate in the completion of the teaching objectives. Nowadays, the change of teaching mode should be a process which teachers and students cooperate and participate together. The changing process of the relationship between teachers and students has a variety of expression forms such as teachers can devote more enthusiasm and input to teaching and make 
students fully ease in the aspect of learning motivation and pressure; Develop students' common hobbies and they will be eager to acquire knowledge; Make autonomy and enthusiasm as emotional guidance then students can overcome the anxiety behaviors. The effective exchange of roles between teachers and students can make the students become the guide and subject of classroom teaching emotions. In the cheerful and pleasant circumstances and a confident learning environment, students would do a good job on review, preview and study.

\section{Explain the Emotional Anxiety of Learners in Learning}

Learners will inevitably have emotional anxiety especially in learning process as they may not quickly grasp all the learning knowledge. Therefore, in the process of learning or kinds of examinations which are to check the education effect, learners are likely to generate emotional anxiety during the learning process for several reasons: For example, learners may have fears and concerns on knowledge due to its difficulty. Another example, it is likely that learners would be anxious because they can't grasp the context in learning process and coherently learn. Or learners may compete with other students in learning process and can't achieve good academic performance in the examination process. The pressure comes from school competition and family may make learners generate anxiety in learning process; There also have some students who are active learners or students who are studying for employment. If the learning theory can't be applied to actual life process, the learners are likely to be confused.

Relationships between Emotional Attitudes and Learning Processes and Outcomes. There is no doubt that the emotional attitude on learning process and results will inevitably bring different results. In the teaching process, many researchers have found that the initiative and enthusiasm of the teaching emotions will naturally better promote the student's learning process. In fact, from the anti-side if learners are anxiety, fear and tension in the process of learning and naturally can't get a better learning effect. Because learning is a self-reflection and internalization process, so if the learners have too volatile emotions, lack of self-confidence and have no enthusiasm or attention, it would naturally impossible to obtain the original teaching purpose. At the same time, learning emotions run through the whole learning process. It has the facilitation effect in learning process and will affect the final learning outcome.

Self-Learning Anxiety Behavior of Students in the Flipped Classroom. Flipped classroom, also known as "inversion classroom teaching mode " or simply inverted classroom and inversion classroom. Flipped classroom comes from a attempt by two chemistry teachers at Woodland Parker High School in Colorado, USA. The origin of flipped classroom teaching is that some students delayed their class due to long distance between school and home. Teachers use the PPT screen capture function to record courses and then released to the Internet for students to learn and achieved good results. The reason why flipped classroom was so successful is that they used inquiry-based learning and project-based learning. It makes students take the initiative to learn.

Learning anxiety from self-learning refers to a certain degree of enthusiasm and autonomy that the learners had in learning process. But for the autonomy growth and knowledge learning process is not very mature, learners in learning not only have learning motivation, but also have a certain pressure. But when mining their own potential, the students don't have the subjective initiative. Although learners are eager to acquire knowledge, but due to improperly using methods or the differences between their own qualities, it is likely to be difficult to understand and be anxious in the process of doing comprehensive knowledge assessment.

Interactive Anxiety Behaviors in Flipped Classroom. Interactive learning anxiety comes from the differences in personal qualities make the actual results of the students are different in the learning process after learning with video although the textbooks are the same in the process of video teaching. Some students have poor academic performance, some students have poor academic performance and some students have poor academic performance. In the course of conducting modern comprehensive examination system, the comprehensive examination result of different students is different. The difference in learning performance during learning activities would lead anxious mood to students. 


\section{How to Teach Learners Self-Control in the Flipped Classroom}

In this case, the learner must use the teaching method and mode of flipped classroom to carry out the regulation of their own. Whether it is because of learning clues and methods or adjustment in learning content and mood, the class should take students as the main body and fully understand the principles of keeping calm to carry out self-regulation and emotional optimization.

Objectively Guide the Learners from the Subjective Self-Regulation Work. Objective guidance the learners to do self-regulation work, that is to say students should memory the learning process after flipped classroom. Associate the learned knowledge and context, compare and summed up the advantages of learning and induction. Finally gain the ability of making summary of knowledge. Students should achieved the purpose of learning self-regulation especially in subjective behavior and make their thinking be clear when needed. But the students should be more confident on on-the-spot performance in learning or examination process.

Through Scientific Methodology and Learning Strategies to Guide Self-Regulation. Scientific learning theory and strategies will naturally lead students to do effective self-regulation and can help students to get better results in the process of learning. Under the effective guidance of teachers, students can grasp the content in a shorter time. Make use of flipped classroom to let students recognize their own strengths and weaknesses in the process of self-learning and review. Try to overcome the shortcomings in learning process, pair work with teachers and students around to a special combination and play different roles. Use scientific methods to improve results. In this case self-anxiety will gradually weaken.

Combined with Communication Methods of Teachers and Students Interactive to Optimize Self-Control. Communication methods of teachers and students interactive can better optimize self-regulation. Students tend to respect teachers very much. As adults, if teachers can be good at teaching and kindly guide students, they can learn more. Teachers and students can make attempt that is good for both of them in learning process, which will help them to get along well and progress rapidly. Besides, it can also optimize teaching methods and improve the feeling and interaction between teachers and students. Finally, students will learn more consciously and achieve good academic performance, and teachers will get a good teach effect.

\section{Conclusion}

Students should be brave to practice, explore, innovate and work hard on summing up. Under what have been mastered, make use of the innovation of flipped classroom teaching mode; do research on emotional communication current situation of learners to improve the existing learning methods to varying degrees. Combine the actual situation of students with effective teaching methods can make them be more confident and play the role of learning main body. In the case of higher learning efficiency, keep students away from the passive learning process. So that learners' anxiety would effectively be balanced by self-confidence and their pressure would be controlled within a reasonable range.

\section{References}

[1] H.J. Liu: Study on the Application of Inverted Classroom Model in English Grammar Teaching in Senior Middle School, (Shanghai International Studies University, China, 2007)

[2] L. Lan: Empirical Study on High School English Writing Teaching Design Based on Inverted Classroom, (Central China Normal University, China, 2016)

[3] L.B. Tang: Study on the Evaluation of the Effect of Geography Teaching in Senior High School, (Central China Normal University, China, 2016)

[4] M. Li: A Practical Study of "Flipped Classroom" in Senior Chemistry Teaching, (Central China Normal University, China, 2016)

[5] X.Y. Lu: Flipped Classroom and Practice Case Study, (China West Normal University, China, 2016) 
[6] D.D. Li: Study on the Anxiety of Rural Junior Middle School Students in English Learning, (Xi'an International Studies University, China, 2015)

[7] R. Guo: Survey of English Learning Anxiety in English Poor College Students, (Liaoning Normal University, China, 2015)

[8] F.L. Zu: Study on English Learning Anxiety in English Poor College Students, (Shaanxi Normal University, China, 2014)

[9] X.W. Yuan: The Application of Emotional Teaching Method in College English Classroom Teaching (Jilin University, China, 2014)

[10]K. Chen: Study on Foreign Language Learning Anxiety of Contemporary College Students Based on Social Constructivism, (Chengdu University of Technology, China, 2013)

[11] S.C. Xiong: Study on the Relationship between Language Learning Anxiety and Learning Strategies in College Students under the Network Environment, (Study on English Classroom Anxiety of College Students in Northwest China, 2012)

[12] J. Wang: Study on English Classroom Anxiety of College Students in Northwest China, (Study on English Classroom Anxiety of College Students in Northwest China, 2007) 